\title{
Using videos and video-conferencing to traverse transactional distance
}

De Jesus, Rameses $\$

University of the Philippines Open University, Philippines (rameses.dejesus@upou.edu.ph)

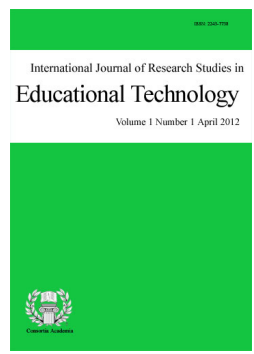

Received: 1 June 2017

Revised: 15 June 2017

DOI: $10.5861 /$ ijrset.2017.1851

Accepted: 13 July 2017

ISSN: $2243-7738$

OPEN ACCESS

\section{Abstract}

Transactional Distance, first introduced in the 1980's, is a significant dimension of learning with far-reaching implications on distance education. As online distance education continues to grow, understanding and navigating transactional distance becomes imperative in the evolving and continually digitizing context of the academia. The use of videos and video-conferencing has become a popular addition to online teaching. This descriptive paper explores the ways videos and video-conferencing help learners and educators traverse transactional distance in the online provision of higher education. What affordances do videos and video-conferencing offer to navigate the transactional distance in online courses? The use of videos and video conferences through open platforms is discussed using Moore's (2007) types of interactions and factors for managing transactional distance and Park's (2011) mobile learning framework, along with instructor observations and student perceptions gathered through surveys. Information in this paper aims to aid online educators as they seek to bridge the transactional distance with their learners.

Keywords: transactional distance; mobile learning; synchronous learning; asynchronous learning 


\section{Using videos and video-conferencing to traverse transactional distance}

\section{Introduction}

This paper explores the use of videos and video-conferencing to help navigate transactional distance as an element in online distance education. Transactional distance is the psychological space between the learners and the instructors. Advances in electronic, mobile, and ubiquitous learning have come to the aid of educators and learners in traversing this space. While there are various ways to navigate transactional distance, this paper looks at the two mentioned educational tools and examines the ways the use of videos and video-conferencing help instructors traverse the transactional distance with learners.

A contemporary expanded understanding of Transactional Distance has been offered by Park in 2011 (adapted from Moore, 2007). Park (2011) summarizes the concept of transactional distance as follows:

This theory was derived from the concept of 'trans-action,' which is considered by many scholars to be the most evolved level of inquiry, compared to self-action and inter-action (Dewey \& Bentley, 1946), and 'the interplay among the environment, the individuals and the patterns of behaviors in a situation' (Boyd \& Apps, 1980, p. 5). Thus transactional distance is defined as the 'interplay of teachers and learners in environments that have the special characteristics of their being spatially separate from one another' (Moore 2007, p. 91). In short, transactional distance is the extent of psychological separation between the learner and the instructor (Moore, 2007; Shearer, 2007). (p. 84)

The discussion on transactional distance has come to involve a few ideas. For instance, Moore proposes that there are three types of interactions in transactional distance (Moore, 2007):

$>$ Learner-Content (or learning material)

$>$ Learner-Expert (or instructor)

$>$ Learner-(fellow) Learner

There are also three factors (Moore, 2007) to consider in managing transactional distance:

$>\quad$ Structure (program, infrastructure of the learning environment, policies and culture)

$>\quad$ Dialog (the interaction between instructors and learners, including among themselves)

$>$ Learner Autonomy (how the learner's autonomy in terms of time use, independent access to material, degree of socialized/individual involvement, and many others).

Park (2011) has offered a range of transactional distance from being low or high, as well as the learning activities used as being either individualized or socialized. The idea of Mobile Learning has also been introduced in this framework. Contemporary technology has allowed for videos and video-conferencing to be accessed not only on stationary devices, but now on mobile devices as well.

This paper examines such use under Park's (2011) expanded pedagogical framework. The use of video sites for viewing, creating, and sharing videos, and video conferencing for learning are categorized according to Park's types of mobile learning. Furthermore, their potential for navigating transactional distance in an online learning environment is also analyzed via Moore's types of interactions and three factors for managing transactional distance. Teacher observations and student responses to survey questionnaires regarding their consumption and creation of information through video-sharing sites, and participation in online video-conferencing are incorporated in the discussion of this paper. 


\subsection{Objective}

This paper wishes to answer the following questions: In what ways do videos and video-conferencing help instructors and learners traverse the transactional distance in online courses? What affordances do they offer learners and instructors in online courses?

\section{Literature review}

\subsection{Transactional Distance: Adopting a contemporary framework}

Transactional Distance was first articulated by Michael Moore in the late 1970's, and in 1980, he published materials on transactional distance. This concept has since had a significant impact on distance education, from its beginnings as correspondence education, to what has now become predominantly Online Education. Developments in technology are coming to the aid of distance learners and provide ways to traverse transactional distance. Moorhead, Colburn, Edwards, and Erwin (2013) explain, “...Online education can provide individualized learning for students since access to online courses usually is not limited to specific days or times; therefore, online instructors and students theoretically never miss a class" (p. 3). Developments in technology thus allow flexibility and mobility of learning, in terms of accessing and engaging materials individually, as well as participating in both individualized and socialized learning activities and assessments.

\subsection{Park's pedagogical framework: Four types of mobile learning}

As interest in online learning increases, an understanding of contemporary elements and factors influencing transactional distance in the online context is warranted. A pedagogical framework for mobile learning has been developed by Park (2011). This framework pays special attention to transactional distance, learning activities, and the use of mobile devices for learning. He proposes Four Types of Mobile Learning, among which you can classify learning activities that occur in the learning space (see Figure 1).

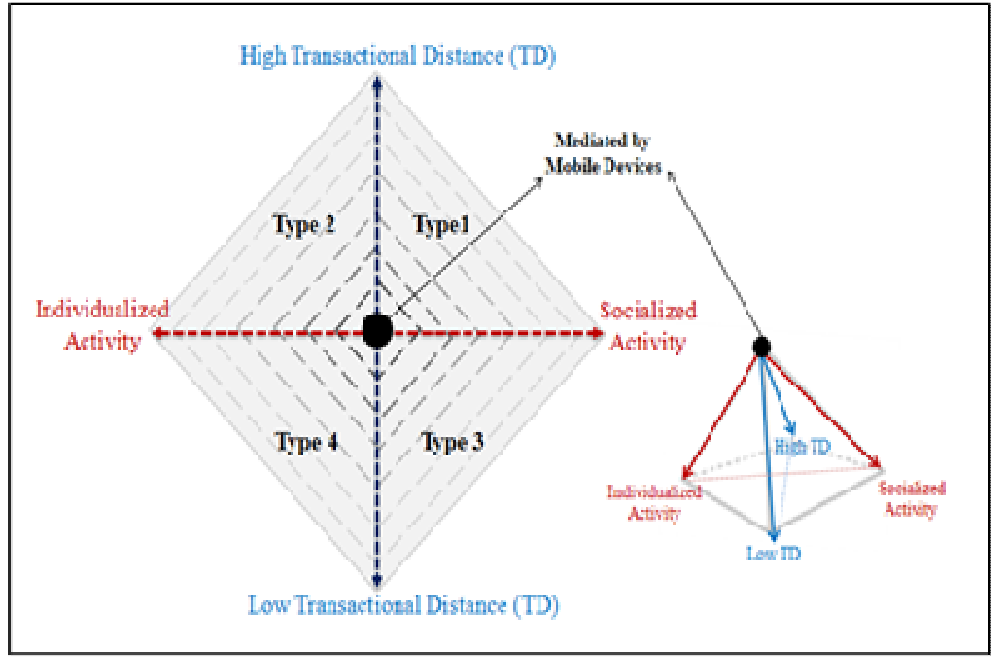

Figure 1: Four types of mobile learning: A pedagogical framework (Park, 2011)

Salient features of each type of mobile learning, according to Park, are as follows:

Type 1: High Transactional Distance and Socialized Mobile Learning Activity (HS)

The learners have more psychological and communication space with their instructor or institutional support;

$>\quad$ The learners are involved in group learning or projects where they communicate, negotiate, and collaborate with each other. 
Type 2: High Transactional Distance and Individualized Mobile Learning Activity (HI)

$>$ The individual learners have more psychological and communication space with the instructor or instructional support;

$>$ The individual learners receive the content and control their learning process in order to master it;

$>$ The interactions mainly occur between the individual learner and the content.

Type 3: Low Transactional Distance and Socialized Mobile Learning Activity (LS)

$>$ This type demonstrates the most advanced forms of versatility of mobile devices and learners' social interactions; here there is less psychological and communication space with the instructor;

$>$ Students engage in social interaction, negotiation, and frequent communication naturally.

Type 4: Low Transactional Distance and Individualized Mobile Learning Activity (LI)

$>\quad$ Less psychological and communication space between instructor and learner;

$>$ Loosely structured and undefined learning content;

$>$ The instructor leads and controls the learning in an effort to meet individual learners' needs while maintaining their independence; this type shows characteristics unique to mobile learning that support blended or hybrid learning (2011, Educational Applications of Mobile Technologies, para. 2-18).

Park's framework helps us understand how the use of mobile technologies such as videos and video-conferencing aid in traversing transactional distance. To emphasize, transactional distance is not necessarily a "barrier" to the interaction, it is simply an inherent part of an educational set-up, especially in distance education. Instructors best be mindful of this gap, and work towards managing or bridging it. Oliver (2015) notes:

The obvious effect of people being physically separated in online education can ultimately result in a number of issues. Students may feel disconnected with either the material that is being taught, their fellow students or instructors, or they may not identify with the program altogether. This leads to negative side effects such as lower student engagement (Kahn, 2008), lower student performance (Pascarella, Seifert, \& Blaich, 2010), and higher dropout rates (Yasmin, 2013, p. $1)$.

Hence, using videos and video-conferencing as means of interacting with students can be ways of reducing the transactional distance between instructor and learner as psychological and communication spaces are negotiated, and as students are offered individualized or socialized opportunities for learning, in synchronous or asynchronous modes.

\subsection{Utilizing Videos in Online Learning}

The use of videos helps teachers and learners navigate transactional distance by providing audio-visual modes of engaging and producing content. In online courses, students may view video materials that may be informative in various ways - expository, persuasive, demonstrative, evaluative, and many others. Oliver (2015) explains that videos draw and connect learners together, as the learners are "exposed to real human faces online, which ultimately leads to a higher fidelity and can also help with establishing a sense of community" (p. 1). He argues that "fidelity counteracts the feeling of isolation in an online environment" as they see the faces of peers and instructors (p. 1). Moreover, students can also create their own informational videos that show interviews, skills demonstration sessions, topic presentations, and other relevant learning activities. Laaser and Toloza (2013) expound, "Producing videos on your own implies that you have to come into direct contact with objects, people, situations, and processes, not by just watching another video or reading a book" (p. 273).

Videos allow for the three types of interaction (Moore, 2007) in transactional distance to occur in asynchronously in online education. The instructor's provision of video resources, study guidelines, and related 
feedback, as well as the students' access of videos (viewing and uploading), and sharing of comments and video resources need not happen at the same moment for interactants. The capacity for asynchronous access allows for flexibility of learning. Given that most web-based video sites are now also accessible on mobile devices, the opportunities for mobile learning also allows students a great deal of leverage in choosing when and where they would commence learning for a course.

The interplay of the three factors (Moore, 2007) for managing transactional distance must also be considered. The Structure can be set by the instructor so that it is clear to the students that course materials may be engaged or submitted at the time of their preference (within the parameters set in the course). While the Dialog between instructor and learner may be asynchronous, this is precisely what affords the students more Learner Autonomy - they will not be bound to fulfill such requirements all at the same moment, and they can exercise a greater degree of self-directedness regarding their own learning. Hence, while the transactional distance may be "High" in asynchronous activities, as Park (2011) would categorize it, this can also be navigated efficiently in terms of learning flexibility.

\subsection{Utilizing Video-conferencing in Online Learning}

Video-conferencing has a different nature in that the learning activity happens at the same time for all participants (synchronous learning). The three types of interaction in transactional distance proposed by Moore (2007) is more apparently supported by video-conferencing (Karabulut \& Correia, 2008, in Cordie, 2014). Video-conferencing allows "the synchronous integration of screen sharing, text chat, audio streaming, and video streaming" (Steed \& Vigrass, 2011, p. 1). These elements create the ground for interaction between instructor, learners, and content for discussing topics, sharing feedback with others, sharing resources, and offering assessment of performance in tasks.

Despite the variety of locations of students in online distance classes, video-conferencing provides instructors the opportunity to interact with students in a synchronous learning activity. Video-conferencing thus substitutes for what would be face-to-face discussions in traditional classrooms. As Greenberg (2004) points out, "With video conferencing, the real-time, two-way visual and verbal interaction of the bricks and mortar classroom could be simulated by technology - creating a 'virtual classroom' whose boundaries were limited only by the extent of the video conferencing network" (p. 3).

The three factors for managing transactional distance also come into play. In the Structure of the course, the proceedings and expectations of video-conferencing as a learning activity may be set by the instructor so as to achieve specific outcomes (e.g. information sharing, assessment). Video-conferencing may be with individual students, or a group of students at once. The sessions may be structured, semi-structured, or unstructured interviews or conversations. The Dialog between learners with instructors and fellow learners are synchronous, lending themselves to goals that are often set by the instructor. Learner Autonomy is decreased, save for the flexibility afforded possibly by a few options on session time slots, and individual input into the conversation. Transactional distance will be "Low" in synchronous activities, as Park (2011) would categorize it, and the interaction would often yield decreased psychological and communication space between instructors and learners.

\section{Method}

This paper is a descriptive study on the use of videos and video-conferencing in the provision of online higher education. It describes online students' perceptions and instructor observations of such technological applications for traversing transactional distance. The survey method was utilized to gather student perceptions on the benefits and affordances (as well as difficulties) they encountered in using videos and video-conferencing. Instructor observations were also noted, and were used to complement the data gathered from the students. 


\subsection{Participants}

Students of two different online classes (Class A and Class B) in an online higher education institution were the respondents of this study. They were surveyed accordingly about using videos and participating in video-conferencing.

Class A was composed of 58 students who were asked to view instructor-selected videos online, and were also asked to create and share videos as part of their learning activities and assessment. They used open access platforms. Out of 58 students, 35 responded to the questionnaire. Their ages ranged from 24 to 56, with 28 years old being the mode. Of the respondents, there were significantly more females (27) than males (8). The respondents were located across various cities around the globe: Bangkok, Chiang Mai, Phuket, Chonburi, Milan, Riyadh, Hangzhou, Singapore, Baguio, Quezon City, Cavite, Muntinlupa, La Union, Aklan, Calamba, Antipolo, Pasig, Mandaluyong, Lumban, Cebu, Tagum, Marikina, Caloocan. Ninety-one percent of the respondents (32 out of 35) were employed.

On the other hand, in Class B, 33 undergraduate students participated in video-conferencing as part of their learning and feedback activities. Out of 95 students, 33 participated in an optional video-conferencing activity, and 23 of those responded to the survey questionnaire. Their ages ranged from 18-39, with 21 years old being the mode. There were 12 male respondents, and 11 female respondents. All participants were located in cities or provinces within the Philippines.

\subsection{Data Collection and Instrument}

To gather student perceptions, two survey questionnaires were administered: one for the use of videos in Class A, and another for the use of video-conferencing in Class B. The questionnaire administered to Class A asked about the students' experiences in viewing, creating and sharing videos for the class. Some of the questions included were:

$>\quad$ How has using video sites helped in your learning in terms of accessing new information, creating information through own videos, reviewing own videos for self-assessment, reviewing related information, and many others?

$>\quad$ On which types of devices have you used video sites for class?

$>\quad$ In what locations/places did you access video sites for class?

These questions looked into the affordances of using videos for learning, such as mobility of access, flexibility in terms of schedule of accessing, as well as perceived benefits of the learning activity.

A separate questionnaire was administered to Class B. It contained questions that asked about the advantages and difficulties encountered in participating in videos-conferencing for class. Some of the questions are:

$>\quad$ Which device did you use for the video-conferencing activity?

$>\quad$ At what venue did you conduct the video-conferencing activity?

$>\quad$ What difficulties did you encounter using Skype for the video conference (if any)?

$>\quad$ What advantages did Skype offer for this activity?

Correspondingly, these questions looked into the affordances of using video-conferencing for learning, such as mobility of access through types of device used, locations when participating, as well as perceived benefits of participating in the learning activity.

To ascertain clarity and relevance of the questions included, the questionnaires were piloted to previous students who went through the same learning activities of viewing, creating and sharing videos, as well as participating in video-conferencing with the instructor and fellow learners. Furthermore, as a complement to 
students' perceptions, instructor observations were also noted regarding the incorporation of videos and video-conferencing in the online classes. Observations regarding logistics and administration of the learning activities were noted, as well as noteworthy factors and considerations.

\section{Results}

The questionnaires asked for demographic information, and then asked questions pertaining to the use of videos (for Class A), and video-conferencing (for Class B). The following information were gathered from the survey:

\subsection{Class A - Use of Videos}

Based on the responses, the types of device used in accessing/creating/sharing videos for the course varied, with mobile devices comprising the majority: laptops are the mobile device of choice, followed by handheld phones (See Figure 2). Regarding the locations where students accessed course videos, all students accessed video sites at their home, and close to half accessed video sites at their office (see Figure 3).

Figure 2. Devices Used to Access Video Sites for

Class

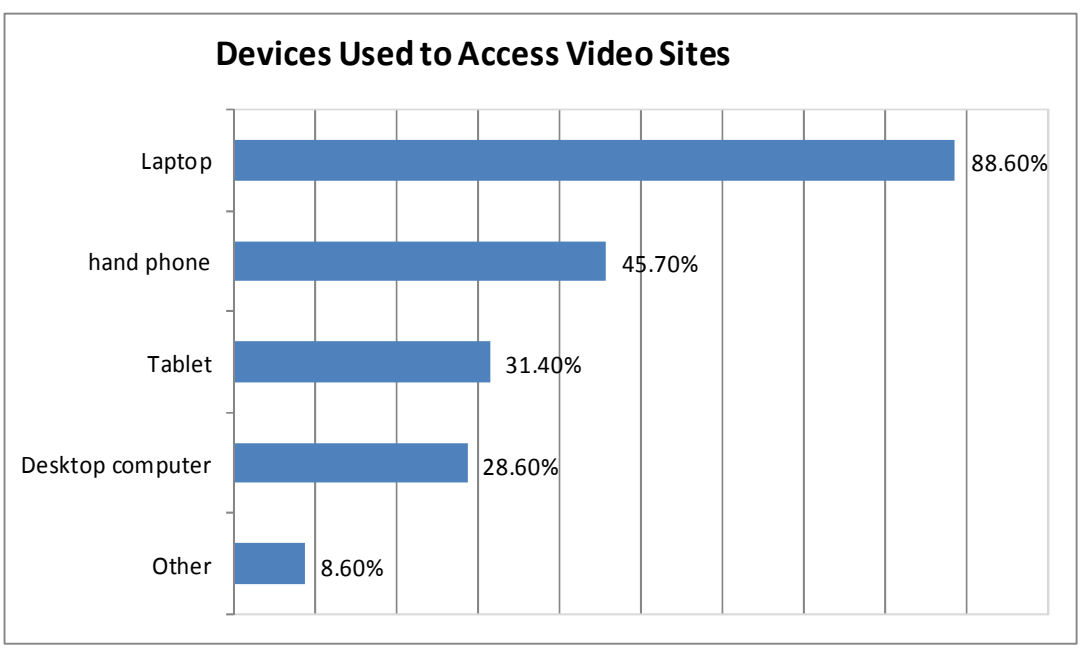

Figure 3. Venues Where Video Sites Were Accessed

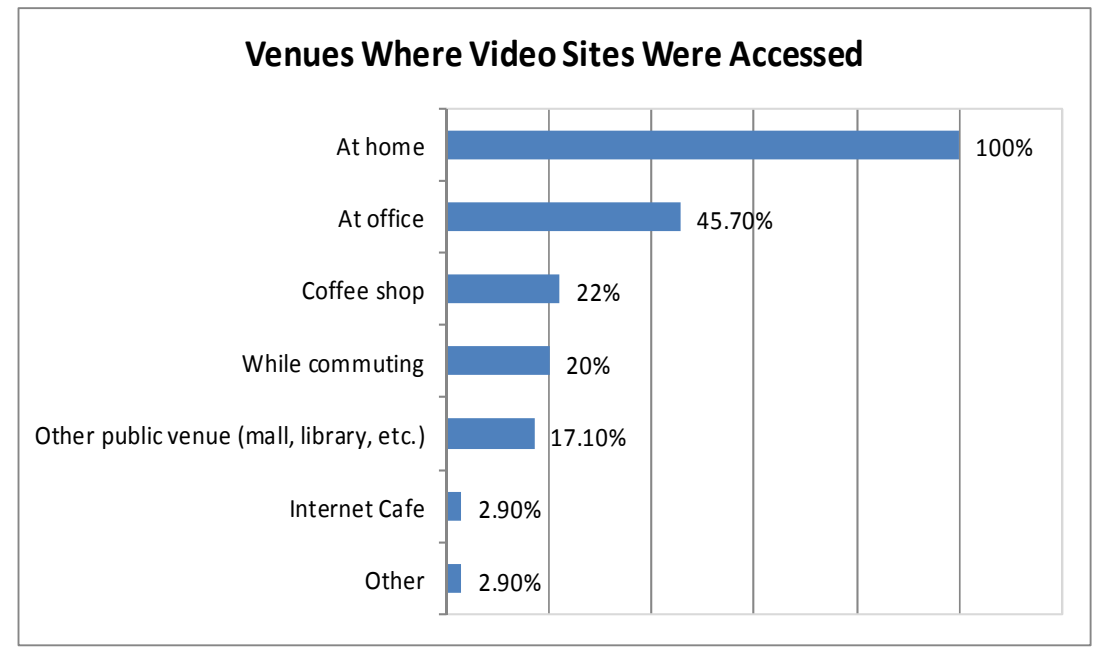

According to all the respondents, the use of video sites is useful to learning. However, difficulties were encountered when using video websites/applications. Some of these were: slow internet connection; slow uploading/viewing; compatibility of video sites with mobile devices being used (see Figure 4).

In addition, based on the students' responses, the affordances of using video sites for viewing instructor-selected and student-generated videos can be categorized as pedagogical or technological. 
De Jesus, R.

Pedagogical affordances refer to advantages and benefits to the teaching and learning process through the use of videos. Students reported that these include sparking interest in the topics, sharing knowledge with peers, and having authentic learning opportunities. On the other hand, technological affordances refer to advantages and benefits inherent to the technology of using videos for class. Students said that these include accessibility, cost-effectiveness, and capacity for multiple information review. Table 1 (below) summarizes the affordances of using videos for class according to the students' responses.

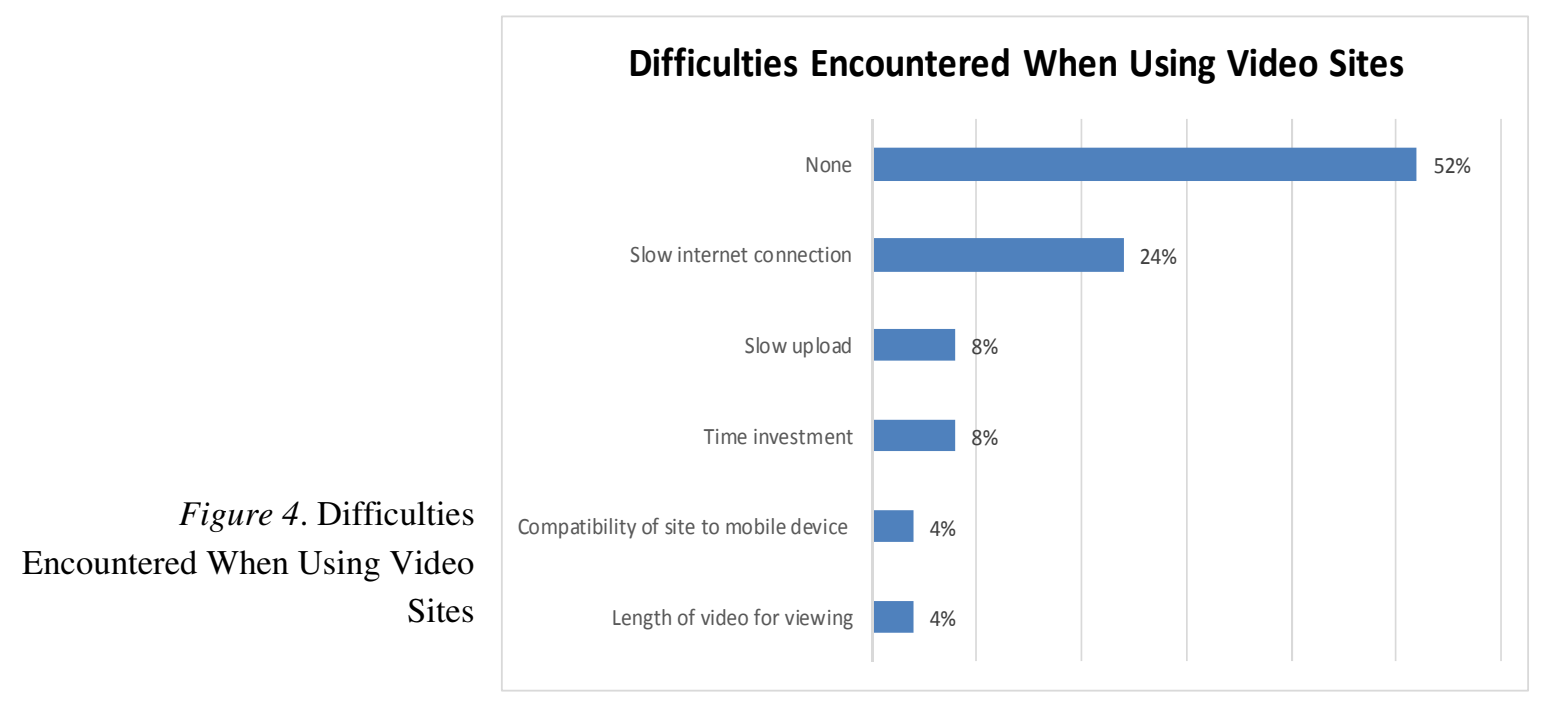

\section{Table 1}

Affordances of Using Videos in an Online Higher Education Class

\begin{tabular}{|c|c|c|}
\hline \multicolumn{3}{|c|}{ Pedagogical Affordances } \\
\hline Affordances & Description & Example \\
\hline Comprehension & Facilitates understanding & $\begin{array}{l}\text { "Videos can clearly show how } \\
\text { something is done and should be done, } \\
\text { the clarity, credibility and also } \\
\text { persuasiveness can affect my } \\
\text { understanding on a certain topic that is } \\
\text { related to the video, something in } \\
\text { detail becomes more vivid." }\end{array}$ \\
\hline Interest/motivation & Fosters interest & $\begin{array}{l}\text { "It increases interest in and attention to } \\
\text { information." }\end{array}$ \\
\hline Knowledge sharing/peer-teaching & Facilitates exchange of ideas & $\begin{array}{l}\text { "It allows us to share insights and } \\
\text { information to others who also study } \\
\text { the same subject." }\end{array}$ \\
\hline Self-directed learning & $\begin{array}{l}\text { Allows ownership and taking } \\
\text { responsibility for learning }\end{array}$ & $\begin{array}{l}\text { "It allows me to view the video as } \\
\text { many times as I want which proved to } \\
\text { be helpful when I needed to clarify } \\
\text { some information or needed to review } \\
\text { the topic being discussed." }\end{array}$ \\
\hline Authentic learning opportunities & $\begin{array}{l}\text { Allows real, concrete and/or } \\
\text { experiential learning }\end{array}$ & $\begin{array}{l}\text { "It helped because I saw how it is to } \\
\text { conduct the activity." }\end{array}$ \\
\hline Multi-modal learning & $\begin{array}{l}\text { Accommodates multiple avenues of } \\
\text { learning }\end{array}$ & $\begin{array}{l}\text { "Videos with written transcription are } \\
\text { useful learning tools for visual learners } \\
\text { like me. I need to see and if possible } \\
\text { hear the information and learning." }\end{array}$ \\
\hline
\end{tabular}


Using videos and video-conferencing to traverse transactional distance

Table 1 ...continued

\begin{tabular}{|c|c|c|}
\hline \multicolumn{3}{|c|}{ Pedagogical Affordances } \\
\hline Affordances & Description & Example \\
\hline Observational learning & Shows models for skills and behaviors & $\begin{array}{l}\text { "Seeing the actual [facial] expressions } \\
\text { and subtle [nonverbal] things that a } \\
\text { learner must be aware of." }\end{array}$ \\
\hline Knowledge acquisition & Introduces new information & $\begin{array}{l}\text { "It helped a lot in learning and } \\
\text { acquiring new skills." }\end{array}$ \\
\hline Procedural knowledge & Introduces or demonstrates approaches & $\begin{array}{l}\text { "You can get some ideas on its } \\
\text { process, techniques, ideas which you } \\
\text { can apply." }\end{array}$ \\
\hline Technical knowledge gain & Facilitates technical know-how & $\begin{array}{l}\text { "It was an entirely new way of } \\
\text { learning as this was the first time I } \\
\text { used the video sites for learning } \\
\text { purposes. I now know how those } \\
\text { videos I watch get uploaded." }\end{array}$ \\
\hline Novelty & $\begin{array}{l}\text { Allows new or non-traditional ways of } \\
\text { engaging course materials }\end{array}$ & "Innovative way of learning." \\
\hline \multicolumn{3}{|c|}{ Technological Affordances } \\
\hline Affordances & Description & Example \\
\hline Cost-effectiveness & $\begin{array}{l}\text { Open platforms are available (e.g. } \\
\text { YouTube) }\end{array}$ & "Free." \\
\hline Accessibility & Facilitates easy reach of information & "Make easy access to learning." \\
\hline Familiarity & $\begin{array}{l}\text { Most students have used or know of } \\
\text { the platform }\end{array}$ & "Familiar; I have used it before." \\
\hline User-friendliness & Easy to use, access, navigate & "Easy to use." \\
\hline File size capacity & Allows large-file upload or viewing & "Can upload large-sized files." \\
\hline Information review & $\begin{array}{l}\text { Permits repetition of access to } \\
\text { information }\end{array}$ & $\begin{array}{l}\text { "The opportunity to push the replay } \\
\text { button till eternity is a plus." }\end{array}$ \\
\hline Access to supplementary video resources & $\begin{array}{l}\text { Points to other related resources (via } \\
\text { automatic suggestions) }\end{array}$ & $\begin{array}{l}\text { "Aside from the assigned videos, } \\
\text { related videos to the topic were also } \\
\text { suggested so the information were } \\
\text { really endless." }\end{array}$ \\
\hline
\end{tabular}

The instructor also notes observations on using videos as a learning activity. The use of videos is best incorporated in the course design as a component that relates to rest of the course, and not simply as a scattershot set of resources that do not relate to other components of the learning design. The pedagogical fit must be considered. Videos may be employed in the delivery of content, assessment, and evaluation of the course. Time and labor goes into the design and delivery of learning activities that make use of videos. Selecting materials from various sources permits exposure of students to a variety of presentations, multiple perspectives, and strengths of presenters (or content) that the instructor may not possess. A wealth of video resources is available online that could be used for class. Yet the very same availability of a plethora of information poses the challenge on instructors to locate credible, relevant, accurate, and up-to-date video materials. This has been validated in available literature on the use of videos (Oliver, 2015), hence, allotting sufficient time for this process has been kept in mind.

While the use of web-based videos allows students of the same class that come from various geographic locations to access the same materials, it has been noted that students from specific regions are restricted from accessing particular video platforms or video content. For instance, students based in China may have difficulty 
De Jesus, R.

accessing YouTube. There are also video-content online that are restricted from access in particular countries. Course design must be able to accommodate these circumstances.

\subsection{Class B - Use of Video-Conferencing}

Based on the responses, the types of device used for video-conferencing were mainly mobile devices, with laptops being the most used, followed by tablets (see Figure 5). Regarding the locations where students conducted the video-conferencing, majority of the students were at their home (see Figure 6).

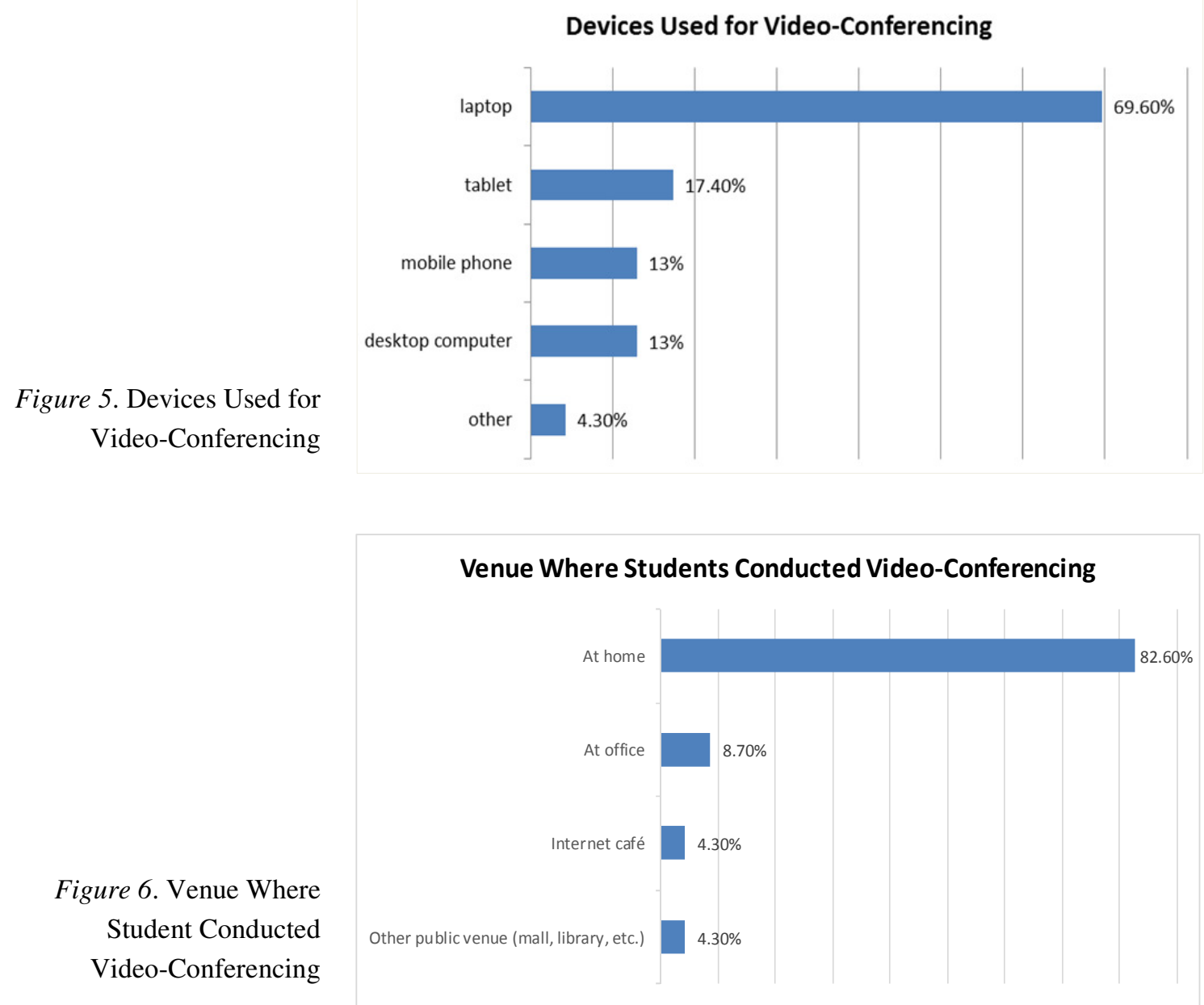

Respondents also reported difficulties encountered while participating in video-conferencing. Slow internet connectivity was experienced by a fifth of the participants, while poor audio was experienced by some.

Figure 7. Difficulties Encountered When Participating in Video-Conferencing

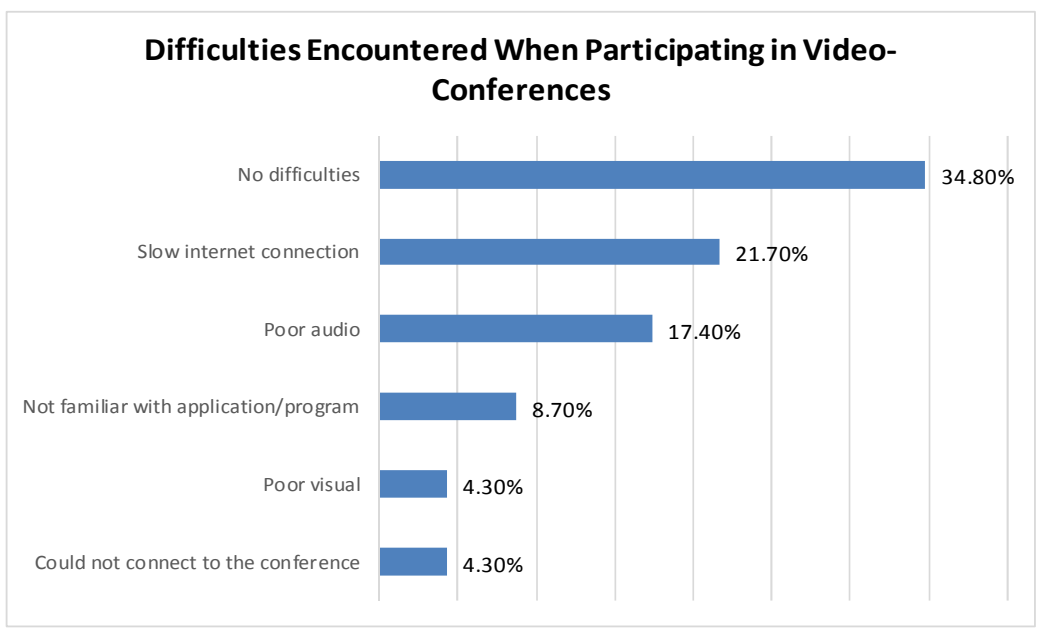


Although some students experienced difficulties, all students reported that they found video-conferencing beneficial to their learning. Similar to the results in the use of videos, the affordances of using video-conferencing can also be categorized as pedagogical or technological. Correspondingly, pedagogical affordances refer to advantages and benefits to the teaching and learning process through the use of video-conferencing. On the other hand, technological affordances refer to advantages and benefits inherent to the technology of using video-conferencing as a learning activity. Based on the students' responses, the pedagogical affordances of video-conferencing include sharing knowledge with peers, authentic feedback, and multi-modal learning. Meanwhile the technological affordances include geographic reach, real-time interaction, and mobility through preferred device. Table 2 (below) summarizes the affordances of using video-conferencing for class based on the students' responses.

\section{Table 2}

\section{Affordances of Using Video-Conferences in an Online Higher Education Class}

\begin{tabular}{|c|c|c|}
\hline \multicolumn{3}{|c|}{ Pedagogical Affordances } \\
\hline Affordances & Description & Example \\
\hline $\begin{array}{l}\text { Authentic feedback (instructor or/and } \\
\text { peer) }\end{array}$ & $\begin{array}{l}\text { Facilitates awareness regarding } \\
\text { performance }\end{array}$ & $\begin{array}{l}\text { "We were made aware of the strengths } \\
\text { and weaknesses of our submitted work." }\end{array}$ \\
\hline High engagement & $\begin{array}{l}\text { Engages learners through on-going } \\
\text { discussions }\end{array}$ & $\begin{array}{l}\text { "It is engaging and it is helpful in } \\
\text { getting an advice from your professor as } \\
\text { well as your co-learners." }\end{array}$ \\
\hline Knowledge acquisition & Introduces new information & $\begin{array}{l}\text { "It gave me ideas for improving my } \\
\text { writing." }\end{array}$ \\
\hline Knowledge sharing/peer-teaching & Facilitates exchange of ideas & $\begin{array}{l}\text { "I gained a lot of insights on critical } \\
\text { writing from interacting with my } \\
\text { classmates and our faculty." }\end{array}$ \\
\hline Comprehension & Facilitates understanding & $\begin{array}{l}\text { "It helped me understand what my } \\
\text { opportunities are." }\end{array}$ \\
\hline Multi-modal learning & $\begin{array}{l}\text { Accommodates multiple avenues of } \\
\text { learning }\end{array}$ & $\begin{array}{l}\text { "Being a visual learner, solely relying } \\
\text { on one modal (text) for lectures and } \\
\text { modules is a torture. Having these } \\
\text { review sessions makes the topics more } \\
\text { engaging and easier to learn." }\end{array}$ \\
\hline \multicolumn{3}{|c|}{ Technological Affordances } \\
\hline Affordances & Description & Example \\
\hline Cost-effectiveness & $\begin{array}{l}\text { Open platforms are available (e.g. } \\
\text { YouTube, Vimeo) }\end{array}$ & "It is free." \\
\hline Familiarity & $\begin{array}{l}\text { Most students have used or know of } \\
\text { the platform }\end{array}$ & "It is familiar." \\
\hline User-friendliness & Easy to use, access, navigate & "Easy to use." \\
\hline Mobility through preferred device & Accessible in mobile devices & $\begin{array}{l}\text { "I could access it in my preferred } \\
\text { device." }\end{array}$ \\
\hline Mobility through location & Accessible in various locations & "I could access it in any location." \\
\hline Real-time interaction & $\begin{array}{l}\text { Synchronous audio-visual } \\
\text { communication }\end{array}$ & $\begin{array}{l}\text { "Seeing your professor and some of } \\
\text { your classmates puts a humanity and } \\
\text { warmth to the course." }\end{array}$ \\
\hline Geographic reach & $\begin{array}{l}\text { Connection of interactants from } \\
\text { various locations }\end{array}$ & $\begin{array}{l}\text { "Can accommodate two or more people } \\
\text { from different locations to have an } \\
\text { opportunity to discuss and share } \\
\text { thoughts." }\end{array}$ \\
\hline
\end{tabular}


Instructor observations on the use of video-conferencing in class are also noted. Similar to videos, the use of video-conferencing is best incorporated in the bigger picture of the course design, so that the pedagogical fit may be considered. Video-conferencing can be used to deliver content, assess student performance, deliver real-time feedback, and evaluate the course itself. Accordingly, time and labor goes into the design and implementation of video-conferencing as a learning activity. Since it is a synchronous activity, scheduling sessions takes a considerable amount of effort for both instructor and learners. The task of gathering an appropriate-sized group at time schedules that fit each participant necessitates planning, time for signing up, and accommodating possible changes in schedules of some participants. A group of seven interactants for hour-long sessions has been set by the instructor, so that there are not too many (nor too few) participants in the exchange. The instructor provided several time slot options for students to choose from. An online sign-up sheet was utilized, so as to accommodate voluntary sign-ups, where students could see time and date options, as well as remaining available slots. The instructor provided instructions and guidelines for signing up for a session, as well as for preparing for the virtual gathering. The instructor also outlined a semi-structured discussion that included covering course content, providing feedback on student performance, and fielding questions from students. As this shows, video-conferencing can be heavily instructor-directed. Both online sign-up, and actual video-conferencing were conducted in open platforms.

The instructor notes that all participants were located in cities or provinces within the Philippines. Video-conferencing was designated as an optional learning activity in class, and the instructor notes that not all students signed up for a session. About $70 \%$ of the students signed up for a video-conferencing session, and only $40 \%$ were able to actually participate. The synchronous nature of this learning activity may prevent some students from participating due to unavailability on proposed times. Some students also expressed that coming from different time zones was a deterrent to participation in the synchronous activity. When some students were not able to attend time slots they signed up for, rescheduling was necessitated, and accommodated where possible.

It is worth noting that the advantages of real-time interaction for the instructor include a more fluid exchange of ideas and feedback with students. Even when the instructor addresses a particular student, fellow learners can gain insight through observation, thus potentially addressing related questions they may have had, or simply adding to insights they gained from the course. Much ground is thus covered in a shorter amount of time when discussing in real-time.

\section{Discussion}

The use of videos and video-conferences in the provision of online higher education is examined in this paper regarding the ways in which they help instructors and learners traverse transactional distance. These technologies can be incorporated in online classes so as to make use of the affordances they offer in bringing instructors and learners together to facilitate learning. As Themelis and Bougia (2016) put it, "Transactional distance theory (TDT) refers to the closeness of the connections between participants in an online [networked learning] environment, and the degree to which this enables them or hampers their ability to construct knowledge and facilitate understanding (Moore, 1980, p. 150)".

There are pedagogical and technological affordances to using videos and video-conferencing in online higher education. These technologies facilitate teaching and learning so that activities can be designed and implemented to suit course goals. Likewise, pedagogy and assessment may be delivered through videos and video-conferencing. A few elements to consider with the use of these technologies are: the three factors and types of interactions in transactional distance proposed by Moore (2007), as well as the types of mobile learning suggested by Park (2011). 


\subsection{Viewing, Creating and Sharing Educational Videos}

Students in this study accessed videos for class at their preferred times. The asynchronous use of videos took two forms:

$>\quad$ Viewing - watching instructor-recommended videos that had content relevant to the course topics

$>\quad$ Creation and Sharing - creating videos for submission/uploading to online video-sharing sites as part of assessment of students' learning and application of knowledge and skills.

Considering Moore's (2007) three factors of transactional distance, the use of videos for class involved:

Structure - The use of videos was incorporated in the design of the curriculum. Given the infrastructure of the online learning environment, open educational resources that allow viewing, creating, and sharing videos facilitated the delivery of course content, as well as assessment of learning.

Dialog - Video-sharing sites fostered interaction between the instructor and learners, as well as among fellow learners, through set instructions, study guides and questions, and sharing of student-created videos with the instructor and fellow learners.

Learner Autonomy - The asynchronous nature of viewing, creating, and sharing videos afforded the students flexibility of learning. This independence allowed for ownership and self-directedness in learning.

Based on the findings of this study and instructor observations, the use of videos facilitated the following interactions (based on Moore's framework), which aided in the navigation of transactional distance:

Learner-Content - By having access to video resources that the instructor pre-selected or provided via online video sites, students were provided the opportunity to interact with course content. Moreover, open access video-sharing sites provided a wealth of additional or supplementary learning materials about various topics relevant to a course. Most of these platforms have an automatic suggestion section where even more related materials were made available to viewers, and the students could the decide to expand their learning by viewing these. The students have also been asked to create their own video content, as part of their requirements for information-generation, assessment, and sharing of knowledge. These were then uploaded to video-sharing sites and these became part of the learning content. A range of dates was set for students to accomplish these, so that they were not bound by time to all be present at once for accessing the video sites. Such activity allowed the students to be part of knowledge creation and sharing - to produce content as opposed to solely consuming content.

Learner-Expert - In this study, the interaction between students and instructor was mediated by the use of videos through the guidance provided by the instructor regarding accessing relevant videos, and submitting/sharing student-generated content. The study guides and questions provided to students by the instructor facilitated the learning and assessment transactions.

Learner-Learner - Accessing videos provided the condition for learner-learner interaction and gave the students the chance to view fellow learners' submissions (where content was not confidential). This type of interaction was also evident in comments offered by students on fellow students' video submissions. When students made their videos available to the public (optional), they also had the chance to receive comments and feedback from the larger public who were seeking to learn about the same topic.

Applying Park's pedagogical framework for understanding the use of videos, it can be said that viewing, creating and sharing educational videos can be classified as: High Transactional Distance and Individualized Mobile Learning Activity (Type 2 - HI). This means that given the asynchronous set up of accessing and sharing/uploading videos, the high transactional distance between the instructor and learner is well navigated through the students' individualized access to the videos. The psychological and communicative interaction between instructor and students is maintained through provided guidelines and feedback. On the other hand, 
mobility and flexibility are highlighted, as students are given room to individually decide where and when to access videos for class. As Ally (2009) put it, "Learners are given the flexibility of accessing the OER from anywhere and at any time and learners can learn in their own context (as cited by Ally \& Samaka, 2013, Making the Transition to Education for All with OER \& Mobile Learning, para. 5)

Furthermore, all the respondents in this study reported that using videos for class has been beneficial, citing pedagogical and technological affordances of this mobile learning activity (wherein they have used mobile devices in accessing video sites). They have reported that the pedagogical affordances include being able to acquire and understand new knowledge and skills, learn through observation, have flexibility with learning times, exchange knowledge with peers, and be engaged in not just one avenue of learning (e.g. text). The technological affordances they reported include accessibility and mobility though various devices and locations, capability for multiple information review, and access to supplementary resources (see Table 1). These affordances help bridge transactional distance existing within online classes.

Analysis of the data gathered from the questionnaire showed that all of the respondents accessed videos for class at home. Despite $91 \%$ of the respondents being employed, only $42 \%$ reported accessing videos at work. While this reflects flexibility, the low rates for accessing video sites in venues other than these two reflect that there is room for greater use of mobile technology. High mobile technology use would have been reflected if all location options were utilized more often by students to access video sites (i.e. accessing it more while commuting, or in coffee shops, or public places). Likewise, although an array of devices could be used to access videos for class, majority (88\%) of the respondents cited laptops as their device of choice. While handheld phones may offer more mobility, only $46 \%$ of the respondents used them to access videos for class. In addition, web access may be restricted in certain geographical localities, thus posing a hindrance to video site access (as previously noted by the instructor). Although flexibility and mobility are among the technological affordances conveyed by the respondents, learners have yet to maximize the full potential of these affordances.

\subsection{Participating in Video-conferencing}

The synchronous nature of video-conferencing provided opportunities for the instructor and learners to interact through discussions of course materials and feedback provision regarding student performance. Furthermore, video-conferencing allowed peers to comment and give feedback to one another, which created the condition for collaborative learning. In this regard, video-conferencing helped learners and instructor traverse the transactional distance by expanding the reach of education, allowing interactivity, accommodating disparate learning styles, allowing appropriate instructional strategies, and being cost-effective (Greenberg, 2004). Themelis and Bougia (2016) also explain that:

[Instructors] can communicate synchronously to bridge transactional distance as a form of immediacy and intimacy: to resolve conflicts, support, and mentor students. SVC [synchronous video communication] may facilitate learning by explaining difficult subjects, participating in problem-based activities, assigning roles as in role-playing, teaching practical skills and procedures, managing synchronous online dialogue, and giving personalized feedback (p. 149).

Taking into account Moore's (2007) three factors of transactional distance, video-conferencing for class as exhibited in the study involved:

Structure - Regarding the structural consideration in managing transactional distance, video-conferencing sessions were incorporated in the design of the curriculum. The infrastructure of online learning allowed for the use of open platforms to conduct synchronous video communication between instructor and learners that facilitated the delivery of course content and live feedback among participants.

Dialog - Video-conferencing fostered real-time interaction between the instructor and learners, as well as among fellow learners, allowing the incorporation of verbal and non-verbal elements in the transaction. The live 
audio-visual communication simulated face-to-face interactions over course materials and student submissions. These video-conferencing features were responsive to the dialog factor that Moore suggested to consider in handling transactional distance.

Learner Autonomy - Given the synchronous nature of video-conferencing, learner autonomy is somewhat limited. Flexibility in terms of scheduling becomes limited to the time slots suggested by the instructor. Learner autonomy is also limited to the individual input students have during the sessions. As the transactional distance is decreased, learner autonomy is also decreased during video-conferencing, but compensated for by the immediacy and facility of feedback and interaction.

Regarding Moore's (2007) three interactions in transactional distance, video-conferencing allowed the following:

Learner-Content - The students engaged learning materials in live discussions as content mastery and assessment of learning were pursued in video-conferencing. During video-conferencing, the instructor and the learners discussed course content and exchanged assessment points on outputs.

Learner-Expert - The interaction between students and the instructor occurred in real-time, an aspect often desired by distance learners. The synchronous audio-visual communication that video-conferencing allowed significantly reduced transactional distance between the students and instructor, as the psychological and communicative interaction occurred in a real-time exchange.

Learner-Learner - Learner-learner interaction was fostered in video-conferencing as students had the chance to interact with fellow learners, and received and offered insight and feedback among themselves. Students shared their thoughts or reflections with peers, as well as asked questions so that learning may be confirmed, challenged, or enhanced by peers.

Employing Park's pedagogical framework, video-conferencing as a learning activity can be classified as: Low Transactional Distance and Socialized Mobile Learning Activity (Type 3 - LS). This means that given the synchronous set up of video-conferencing, the transactional distance between the instructor and learners is greatly reduced during sessions. The respondents in this study have reported that the pedagogical affordances of video-conferencing for class include being able to receive authentic feedback, exchange knowledge with peers, and be engaged in multiple avenues of learning; whereas, the technological affordances of video-conferencing include accessibility and mobility through various devices, cost-effectiveness, and multi-location interaction (see Table 2). On that account, the psychological and communicative distance between instructor and students is bridged by the technologically aided learning activity. Mobility is afforded to the interactants, as students were able use their various mobile devices that could support their participation in video-conferencing sessions for class.

Analysis of the data gathered from the questionnaire showed that the majority of respondents conducted video-conferencing for class at their home (82.6\%), with a mere $8.2 \%$ of respondents participating in video-conferencing while located at their work. It may be inferred that conduciveness of location might bear on the choice of venue. Moreover, although an array of devices could be used for participating in video-conferences for class, majority $(69.6 \%)$ of the respondents cited laptops as their device of choice. While tablets may offer more mobility, only $13 \%$ of the respondents used them for video-conferencing. It may be inferred that screen-size is a factor for usage, as larger screens make for greater ease in seeing fellow interactants, as well as materials presented on screen.

Video-conferencing also assists instructors and learners in traversing transactional distance through the shared real-time audio-visual experience. Themelis and Bougia (2016) highlight some of the unique offerings of video-conferencing that were experienced by the respondents. They posit that, "Educational technologies promise to improve visual, auditory, spatial, and haptic (touch sensitive) aspects of communication" (p. 153). 
De Jesus, R.

Video-conferencing permits learners to detect and recognize nonverbal cues, such as hand and body movements, while engaging in verbal communication (Themelis \& Bougia, 2016). The opportunity to see human faces of instructor and peers, hear their voices, and even see screen-shared materials helped facilitate learning.

\section{Conclusion}

Videos and video-conferencing can be used to traverse transactional distance in online higher education by facilitating the interplay of the three factors for managing transactional distance, as well as the three interactions suggested by Moore (2007). They provide opportunities for asynchronous and synchronous mobile learning, that make use of the interplay among the course structure, dialog, and learner autonomy; and they allow interactions between instructor, learner, and content, in what Park (2011) would classify as either low or high transactional distance, where learning activities could be individualized or socialized. Videos and video-conferencing provide pedagogical and technological affordances that impact instructors and learners navigating the transactional distance of online learning. These learning activities lend themselves to access through mobile devices in open online platforms, thus offering interactivity, flexibility, mobility, and cost-effectiveness, to name a few affordances. These types of mobile learning assist instructors and learners traverse transactional distance efficiently and effectively.

\section{References}

Ally, M., \& Samaka, M. (2013). Open education resources and mobile technology to narrow the learning divide. International Review of Research in Open and Distributed Learning, 14(2), 13-27. https://doi.org/10.19173/irrodl.v14i2.1530

Burden, K., \& Atkinson, S. (2007). Jumping on the YouTube bandwagon? Using digital videoclips to develop personalized learning strategies. Proceedings from ASCILITE 2007: 24th Annual Conference of the Australasian Society for Computers in Learning in Tertiary Education - ICT: Providing Choices for Learners and Learning (pp. 96-98), Singapore.

Burke, S. C., Snyder, S., \& Rager, R. C. (2009). An assessment of faculty usage of YouTube as a teaching resource. Internet Journal of Allied Health Sciences and Practice, 7(1), 1-8.

Cordie, L. (2016). Facilitating interaction: Best practices for utilizing videoconferencing in a blended learning environment. In Proceedings of Global Learn 2016 (pp. 38-45). USA: Association for the Advancement of Computing in Education (AACE).

Fralinger, B., \& Owens, R. (2009). YouTube as a learning tool. Journal of College Teaching and Learning, 6(8), $15-28$.

Greenberg, A. (2004). Navigating the sea of research on video conferencing-based distance education [White paper].

Hoffman, E. (2009). Evaluating social networking tools for distance learning. In Proceedings of TCC Worldwide Online Conference (pp. 92-100). Hawaii: TCC Hawaii.

Laaser, W., \& Toloza, E. (2017). The changing role of the educational video in higher distance education. International Review of Research in Open and Distributed Learning, 18(2), 264-275. https://doi.org/10.19173/irrodl.v18i2.3067

Liu, Y. (2010). Social media tools as a learning resource. Journal of Educational Technology Development and Exchange, 3(1), 101-114. https://doi.org/10.18785/jetde.0301.08

McKimm, J., Jollie, C., \& Cantillon, P. (2003). ABC of learning and teaching web-based learning. British Medical Journal, 326(7394), 870-873. https://doi.org/10.1136/bmj.326.7394.870

Moore, M. (1980). Theory of transactional distance. In D. Keegan (Ed.), Theoretical Principles of Distance Education. London: Routledge.

Moore, M. (2007). The theory of transactional distance. In M. G. Moore (Ed.), Handbook of distance education $\left(2^{\text {nd }}\right.$ Ed.). Mahwah, NJ: Lawrence Erlbaum Associates.

Moorhead, H., Colburn, A., Edwards, N., \& Erwin, K. (2013). Beyond the myth of the pajama party: Delivering 
quality online counselor education and supervision. Paper based on a program presented at the 2013 American Counseling Association Conference, Cincinnati, $\mathrm{OH}$.

Moran, M., Seaman, J., \& Kane, H. (2011). Teaching, learning, and sharing: How today's higher education faculty use social media. Boston, MA: Pearson Learning Solutions.

Oliver, C. (2015). Community of inquiry and video in higher education: Engaging students online. Unpublished manuscript.

Park, Y. (2011). A pedagogical framework for mobile learning: Categorizing educational applications of mobile technologies into four types. International Review of Research in Open and Distance Learning, 12(2), 78-102. https://doi.org/10.19173/irrodl.v12i2.791

Revere, L., \& Kovach, J. (2001). Online technologies for engaged learning: A meaningful synthesis for educators. The Quarterly Review of Distance Education, 12(2), 113-124.

Safran, C., Helic, D., \& Gütl, C. (2007). E-Learning practices and Web 2.0. Paper presented at the ICL2007, Villach, Austria.

Steed, M., \& Vigrass, A. (2011). Assessment of web conferencing in teacher preparation field experiences. In M. Koehler \& P. Mishra (Eds.), Proceedings of Society for Information Technology \& Teacher Education International Conference 2011 (pp. 2736-2743). Chesapeake, VA: Association for the Advancement of Computing in Education (AACE).

Themelis, C., \& Bougia, A. (2016). Tele-proximity: Tele-community of inquiry model. Facial cues for social, cognitive, and teacher presence in distance education. International Review of Research in Open and Distributed Learning, 17(6), 145-163. https://doi.org/10.19173/irrodl.v17i6.2453 
De Jesus, R. 